LISANUL ARAB 10(1)(2021)
(Terakreditasi Sinta 4)

\title{
MOTIVASI MEMBER FOKS INDONESIA MENEKUNI SENI KHAT KUFI MURABBA' (ANALISIS DESKRIPTIF)
}

\author{
Nafis Azmi Amrullah ${ }^{\bowtie}$, Akbar Syamsul Arifin ${ }^{\bowtie}$, Ahmad Miftahuddin ${ }^{\bowtie}$ \\ Jurusan Bahasa Asing, Fakultas Bahasa dan Seni, Universitas Negeri Semarang, Indonesia
}

\begin{tabular}{|c|c|}
\hline Info Artikel & Abstrak \\
\hline Sejarah $A$ & \multirow{7}{*}{$\begin{array}{l}\text { Penelitian ini bertujuan untuk mengetahui motivasi member FOKS Indonesia menekuni Seni Khat } \\
\text { Kufi Murabba'. Metode Penelitian yang digunakan adalah penelitian kualitatif dengan desain } \\
\text { analisis deskriptif. Instrumen yang digunakan adalah angket yang disebar pada member FOKS } \\
\text { Indonesia dan dianalisis menggunakan skala likert. Dari hasil penelitian dapat disimpulkan bahwa } \\
\text { dari } 26 \text { responden, rata-rata sudah menekuni kufi selama } 4 \text { tahun dengan frekuensi mendesain kufi } \\
\text { paling banyak adalah } 4-5 \text { hari sekali. Perangkat yang paling banyak digunakan adalah ponsel dan } \\
\text { teks yang didesain dalam khat kufi murabba' adalah Ayat Al-Quran dan juga nama orang. Motivasi } \\
\text { tertinggi yang mendasari kebanyakan dari mereka adalah motivasi psikologis sebesar } 90,4 \% \text {, diikut } \\
\text { motivasi sosial sebesar } 87,5 \% \text {, motivasi spiritual sebesar } 80,7 \% \text { dan motivasi bisnis sebesar } 75,9 \% \text {. }\end{array}$} \\
\hline 021 & \\
\hline Diset & \\
\hline Dipublikasikan April & \\
\hline 2021 & \\
\hline & \\
\hline khat kufi murahba' & \\
\hline
\end{tabular}

\begin{abstract}
This study aims to determine the motivation of FOKS Indonesia members to pursue Khat Kufi Murabba' Art. The research method used is qualitative research with descriptive analysis design. The instrument used is a questionnaire distributed to FOKS Indonesia members and analyzed using a Likert scale. From the results of the study, it can be concluded that from 26 respondents, on average, they have been practicing Kufi for 4 years with the frequency of designing Kufi at most once every 4-5 days. The most widely used devices are mobile phones and the texts designed in khat kufi murabba' are Al-Quran Verses and also people's names. The highest motivation underlying most of them is psychological motivation of $90.4 \%$, followed by social motivation of $87.5 \%$, spiritual motivation of $80.7 \%$ and business motivation of $75.9 \%$.
\end{abstract}

(C) 2021 Universitas Negeri Semarang

\begin{tabular}{lr}
\hline Alamat korespondensi: & P- ISSN 2252-6269 \\
Gedung B4 Lantai 1 FBS Unnes & E- ISSN 2721-4222 \\
Kampus Sekaran, Gunungpati, Semarang, 50229 &
\end{tabular}




\section{PENDAHULUAN}

Peradaban sebuah bangsa berawal dari seni aksara. Sebelum datangnya Islam, Peradaban Arab sudah tumbuh dari munculnya aksara Arab, yaitu sekitar abad ke-17 SM. Corak Tulisan Arab dipengaruhi aksara Mesir Kuno Heroglif. Flinders Petrie menyebut bahwa temuan manuskrip yang berasal dari Syria dan Palestina lebih mirip dengan tulisan Arab (Zamri Ba'labka 1981). Aksara Arab semakin tumbuh berkembang seiring perkembangan seni Khat yang mengindahkan dan melembutkan tulisannya. Pada awalnya huruf-hurufnya berbentuk simbol sebagaimana di dalam tulisan Nabatea, yang mirip dengan aksara Arab Kuno dan dari sini muncul gaya tulisan Kufi, Naskhi, dan Maghribiy (Zamri Ba'labka 1981).

Seiring berkembangnya agama Islam, Islam tidak sekadar menjadi agama bangsa Arab saja, melainkan juga menjadi agama penduduk Kawasan perluasan. Banyaknya orang 'ajam (asing) yang menerima Islam memuncukan masalah dalam segi bacaan Al-Quran yang berbeda-beda. Pembacaan al-Quran dengan menggunakan Khat Kufi Mushafs agar sulit dimengerti seperti pada kalimah فاقتلوا . Di dalam Khat Kufi Mushaf yang menjadi tulisan utama al-Quran saat itu, titik pada semua kata tersebut tidak ada, sehingga masyarakat Islam yang bukan berbangsa Arab membacanya dengan dua keadaan seperti فاقبلو atau seperti di atas. Setelah mengalami evolusi bertahun-tahun pada akhirnya penyeragaman khat Quran tersebut juga berimbas pada perkembangan seni khat Arab. Perkembangan Wilayah Islam hingga ke seluruh penjuru dunia mengenalkan gaya khat pada masyarakat secara luas.

Salah satu Khat yang memperluas eksistensinya hingga Asia tenggara (Indonesia, Malaysia dan sekitarnya) adalah Seni Khat Kufi. Khat Kufi termasuk khat klasik dan memiliki banyak variasi. Mayoritas Seniman Khat menyatakan bahwa Khat Kufi berasal dari tulisan Nabati, Hirah dan Anbari. Dinamakan sebagai Khat Kufi karena khat tersebut mulai masyhur di daerah Kufah, Iraq. Sebelum wilayah Islam meluas, Khat Kufi adalah tulisan yang tidak mempunyai titik ataupun baris. Bahkan, aksara ini terbagi menjadi dua aliran yaitu yang ditulis secara bebas atau bisa disebut gaya Tahrir dan juga secara geometris dengan mengutamakan presisi ukuran. Pada Zaman sekarang, khat ini tak hanya berfungsi sebagai karya seni belaka, melainkan juga menjadi hiasan di rumah-rumah, masjid dan logo bisnis. Khat Kufi tersebut adalah Khat Kufi Murabba'.

Friend Of Kufi Square atau yang biasa disingkat menjadi FOKS merupakan sebuah komunitas para penggiat seni Khat Kufi Murabba' . Dari sudut pandang keilmuan, FOKS merupakan salah satu aliran disiplin kufi modern dari beberapa aliran-aliran disiplin Kufi Modern yang ada di Dunia ini, yang dengan ciri khasnya menjaga hak-hak dari setiap huruf hijaiyyah dalam setiap penulisannya.

Komunitas ini didirikan pada awal Mei 2010 oleh beberapa guru atau penggiat awal seni khat kufi murabba' di Malaysia. Adapun FOKS INDONESIA sendiri adalah sebuah perkumpulan seni Kufi Square (Kufi Murabba') dari orang-orang Indonesia yang dipelopori oleh para pegiat-pegiat kufi yang aktif dalam kelas pembelajaran kufi Square yang ada di Group FoKS. Di antara para pendiri FOKS adalah Zehn Pamuji (Blitar), Amal Jamaludin (Depok), Qarel Muhammad Hawari Qarnaini (Aceh), Abu Haidar Al-Khawarizmi (Cianjur), Nur Kholis Hadi (Kediri), Mohammad Fachrurrozi (Cirebon), Badrut Tamam Syah (Bangkalan), Muhammad Yasin (Boyolali), dan Zubeir (Bekasi). Tujuan FOKS INDONESIA dibentuk guna memartabatkan seni kaligrafi kufi square di Indonesia. Dengan mengembangkan kufi square ala FoKS, semoga FOKS INDONESIA dapat diterima oleh kufier Indonesia dan juga menjadi acuan terbaik bagi para penggiat Kufi Murabba'

Usaha penyebaran kaidah Khat Kufi Murabba' yang digaungkan oleh FOKS Indonesia lewat media Facebook sejak saat itu bisa dibilang sangat massif. Tercatat hingga hari ini anggota grup FB FOKS Indonesia mencapai 5.000 orang. Para member FOKS tersebut berasal dari berbagai penjuru nusantara dan tentunya memiliki motivasi beragam untuk 
bergabung dalam grup ini. Peneliti tertarik untuk mengkaji bagaimana motivasi para member komunitas FOKSI ini dalam menekuni Khat Kufi Murabba'

\section{PEMBAHASAN}

\section{DEFINISI MOTIVASI}

Lazim dijumpai orang menggunakan kata "motif" untuk menyatakan alasan mengapa ia melakukan hal tersebut. Kata "motif" dan "motivasi" sangat berhubungan dengan penghayatan suatu kebutuhan. Kata "motif" dimaknai sebagai daya upaya mendorong seseorang untuk melakukan sesuatu. Berdasarkan pendekatan kata motif tersebut, dapat ditarik persamaan bahwa keduanya menyatakan suatu kehendak yang melatar belakangi perbuatan. Banyak para ahli yang memberikan batasan tentang pengertian motivasi antara lain adalah sebagai berikut :

1) Mc. Donald yang di kutip oleh Sardiman menyebutkan motivasi adalah perubahan energi dalam diri seseorang yang di tandai dengan munculnya feeling dan di dahului dengan tanggapan terhadap adanya tujuan ${ }^{6}$

2) Tabrani rushan menyebutkan bahwa motivasi merupakan kekuatan yang mendorong seseorang melakukan sesuatu untuk mencapai tujuan ${ }^{7}$.

3) Heinz kock mendefinisikan motivasi sebagai usaha mengembangkan keinginan untuk melakukan sesuatu ${ }^{8}$.

\section{TEORI MOTIVASI}

Untuk mendapatkan gambaran yang komperhesif maka penulis akan meguraikan beberapa teori motivasi sebagai berikut:

Motivasi itu tidak pernah di katakan baik, apabila tujuan yang di inginkan itu tidak baik. Seperti yang telah dijelaskan bahwa motivasi selalu berhubungan dengan kebutuhan, Abraham Maslow membagi kebutuhan menjadi lima bagian secara hieararkis. Konsep kebutuhan Maslow ini di kenal dengan piramida kebutuhan. Maslow menyimpulkan bahwa motivasi adalah kebutuhan-kebutuhan yang mendorong seseorang untuk melakukan serangkaian kegiatan yang mencapai tujuan tertentu.

Untuk lebih jelasnya berikut ini peneliti sajikan deskripsinya :

1. Kebutuhan fisiologis

Kebutuhan fisiologis adalah merupakan jasmani manusia, misalnya akan makan, minum, tidur dan lainnya. Untuk disiplin dengan waktu siswa harus membagi waktu secara efisien siswa harus sehat. Jika siswa sakit maka akan mengakibatkan terganggunya kondidi fisik, yang kemudian akan mengganggu kedisiplinan siswa.

\section{Kebutuhan rasa aman}

Manusia membutuhkan keamanan jiwa. Perasaan yang takut akan kegagalan, kecemasan, kecewa, dendam, ketidak seimbangan mental dan kegoncangan emosi yang lain dapat mengganggu kelancaran aktifitas siswa. Agar siswa dapat meningkat ke arah yang lebih efektif, maka sisiwa harus menjaga keseimbangan emosi, sehingga perasaan menjadi aman dan konsentrasi pikiran dapat di pusatkan pada pelajaran.

3. Kebutuhan mendapatkan kasih sayang dan memiliki

Dengan mendapatkan kasih sayang, seseorang merasa bahwa ia di terima oleh kelompoknya. Merasa bahwa ia merupakan salah seorang anggota keluarga yang cukup berharga. Agar setiap siswa merasa ia di terima dalam kelompoknya, maka dapat di lakukan dengan cara tepat waktu dalam berteman. Hal ini dapat meningkatkan kediplinan siswa. Kebutuhan untuk di akui sama dengan orang lain sering mrndapatkan kasih sayang dan merupakan kebutuhan primer yang harus di penuhi.

4. Kebutuhan memperoleh penghargaan orang lain

Harga diri seseorang timbul dalam hubungannya dengan orang lain seseorang merasa dirinya di hargai orang lain apabila ia merasa bahwa dirinya di anggap penting dalam hal ini tugas guru adalah mencari dalam diri siswa, apa yang membuat siswa itu dia anggap penting.

5. Kebutuhan untuk aktualisasi diri 
Setiap individu memiliki potensi atau bakat masing-masing yang terkandung di dalam dirinya. Kebutuhan aktualisasi diri atau untuk mewujudkan diri sendiri, yakni mengembangkan bakat dengan usaha mencapai hasil dalam bidang pengetahuan, sosial dan pembentukan pribadi.

\section{SENI KHAT}

Dalam

Kamus

Besar

Bahasa Indonesia, Pengertian Seni, memiliki tiga arti antara lain :

a) Seni diartikan halus, kecil dan halus, tipis, lembut dan enak didengar, mungil dan elok

b) Keahlian membuat karya bermutu (dilihat dari segi keindahan dan kehalusannya)

c) Kesanggupan akal untuk menciptakan sesuatu yang bernilai tinggi.

Dari ketiga definisi tersebut, peneliti menggunakan definisi kedua untuk istilah seni. Dalam proses produksi karya seni, seorang seniman tentu bersinggungan dengan media dan teknik yang dipakai, serta cara untuk menikmatinya. Selaras dengan hal tersebut, seni dapat diklasifikasikan menjadi seni audio, visual, dan audio visual.

Salah satu seni visual yang menarik untuk dikaji peneliti adalah Khat. Dalam Bahasa Arab, Khat selain menjadi sebuah seni, namun juga termasuk suatu disiplin ilmu yang mengidentifikasi bentuk-bentuk huruf tunggal, posisinya, dan cara-cara merangkainya menjadi sebuah tulisan yang tersusun rapi . (Hawa, 2007 :1)

\section{KHAT KUFI MURABBA'}

Khat Kufi adalah jenis khat yang tertua dan terklasifikasi menjadi banyak varian lagi. Sebagian besar seniman Khat menyatakan bahwa Khat Kufi berasal dari tulisan Nabati, Hirah dan Anbari. Dinamakan sebagai Khat Kufi karena khat tersebut mulai masyhur di daerah Kufah, Iraq. Sebelum wilayah Islam meluas, Khat Kufi adalah tulisan yang tidak mempunyai titik ataupun baris. Bahkan, aksara ini terbagi menjadi dua aliran yaitu yang ditulis secara bebas atau bisa disebut gaya Tahrir dan juga secara geometris dengan mengutamakan presisi ukuran.

Di awal kebangkitan Islam, para sahabat menggunakan khat ini untuk menyalin mushaf, menulis surat untuk dihantar kepada kerajaankerajaan besar seperti Kisra di Parsi, Hercules di Rom dan raja Mesir. Khat ini tersebar sehingga pelusuk Arab bahkan telah lahir gaya setempat seperti Khat Kufi Maghribi atau Khat Kufi Andalusi (Yahya Wahhab al-Jabburi 1994). Sebelum wilayah Islam belum tersebar luas, Khat Kufi adalah tulisan yang tidak mempunyai titik ataupun baris, bahkan tulisan Kufi ini mempunyai dua cabang pecahannya iaitu ditulis secara bebas yang disebut sebagai gaya Tahrir ataupun secara menggunakan geometri iaitu menggunakan ukuran berserta darjah kesesuaian.

Namun, pada zaman sekarang, khat ini bukan sahaja sebagai tulisan berseni, tetapi khat ini juga menjadi perhiasan untuk rumah-rumah kediaman, masjid dan logo perniagaan. Khat Kufi yang dimaksudkan adalah Khat Kufi Murabba'. Di Malaysia, gaya Khat Kufi Murabba' semakin mendapat tempat untuk masyarakat terutama mereka yang meminati seni kontemporer.

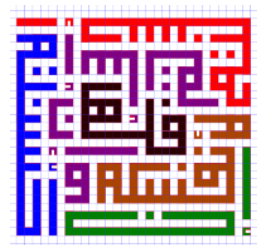

Gambar 1. Contoh Khat Kufi Murabba' (dokumen peneliti)

\section{FRIENDS OF KUFI SQUARE}

Friend Of Kufi Square atau yang biasa disingkat menjadi FOKS merupakan sebuah komunitas para penggiat seni Khat Kufi Murabba' . Dari sudut pandang keilmuan, FOKS merupakan salah satu aliran disiplin kufi modern dari beberapa aliran-aliran disiplin Kufi Modern yang ada di Dunia ini, yang dengan ciri khasnya menjaga hak-hak dari setiap huruf hijaiyyah dalam setiap penulisannya. Kaidah-kaidah khusus tersebut dirumuskan dalam bentuk tabel atau Charta seperti berikut : 


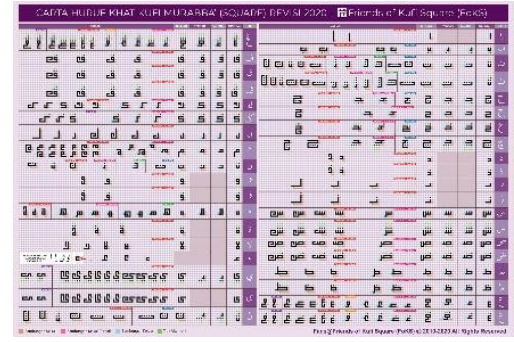

Gambar 2. Charta FOKS

Komunitas FOKS didirikan pada awal Mei 2010 oleh beberapa guru atau penggiat awal seni khat kufi murabba' di Malaysia. Adapun FOKS INDONESIA sendiri adalah sebuah perkumpulan seni Kufi Square (Kufi Murabba') dari orang-orang Indonesia yang dipelopori oleh para pegiat-pegiat kufi yang aktif dalam kelas pembelajaran kufi Square yang ada di Group FoKS. Di antara para pendiri FOKS adalah Zehn Pamuji (Blitar), Amal Jamaludin (Depok), Qarel Muhammad Hawari Qarnaini (Aceh), Abu Haidar Al-Khawarizmi (Cianjur), Nur Kholis Hadi (Kediri), Mohammad Fachrurrozi (Cirebon), Badrut Tamam Syah (Bangkalan), Muhammad Yasin (Boyolali), dan Zubeir (Bekasi). Tujuan FOKS INDONESIA dibentuk guna memartabatkan seni kaligrafi kufi square di Indonesia. Dengan mengembangkan kufi square ala FoKS, semoga FOKS INDONESIA dapat diterima oleh kufier Indonesia dan juga menjadi acuan terbaik bagi para penggiat Kufi Murabba'

\section{METODE PENELITIAN}

Penelitian ini menggunakan pendekatan kualitatif dengan desain analisis deskriptif. Analisis deskriptif adalah jenis analisis yang mencakup pengumpulan, pengolahan, dan penyajian serta penafsiran data atau persentase yang dapat disajikan dalam bentuk tabel atau grafik (Walpole, 1995). Analisis deskriptif bertujuan untuk mengubah sekumpulan data yang masih berupa data mentah menjadi bentuk yang lebih mudah dipahami, yaitu berbentuk informasi yang lebih ringkas. Misalnya menggunakan diagram batang, diagram lingkaran, histogram, ogive, dan sebagainya. Instrumen yang digunakan adalah angket. Pengumpulan data dilakukan melalui penyebaran angket kepada 26 responden yang merupakan anggota FOKS Indonesia. Data yang terkumpul kemudian dianalisis melalui Skala Likert.

\section{HASIL DAN PEMBAHASAN}

Peneliti membagikan angket kepada 26 member Friends of Kufi Square (FOKS) Indonesia, dan berikut adalah hasilnya :

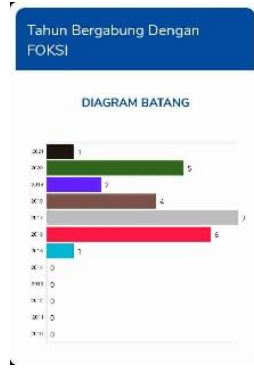

Grafik 1. Tahun bergabung member FOKS

Berdasarkan Grafik 1, dari 26 orang responden, ada sebanyak 7 orang yang mulai menekuni khat kufi murabba' berkaidah FOKS sejak tahun 2017 dan itu adalah yang paling dominan. Selain itu, ada 6 orang yang bergabung sejak tahun 2016, 5 orang yang bergabung di tahun 2020, 4 orang bergabung di tahun 2018, 2 orang bergabung sejak tahun 2019,1 orang dari tahun 2015, dan seorang dari tahun 2021.

Bisa disimpulkan rerata responden sudah menggeluti seni khat Murabba' selama 4 tahun.

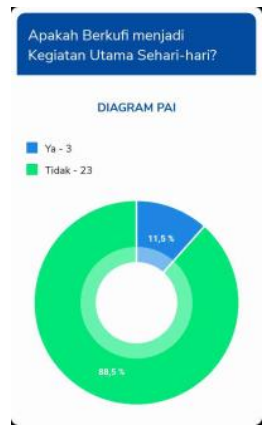

Grafik 2. Prosentase responden yang menjadikan berkufi sebagai kegiatan utama

Berdasarkan Grafik 2, diketahui dari 26 responden, sebanyak $88,5 \%$ tidak menjadikan "berkufi" sebagai kegiatan utama, dan sebanyak $11,5 \%$ menjadikan itu sebagai rutinitas utama mereka. 


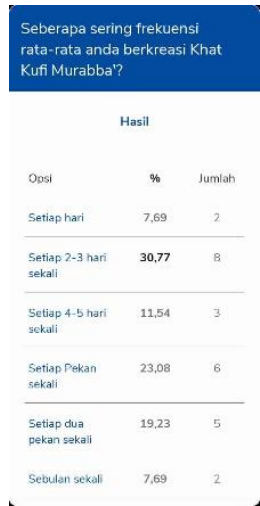

Table 1. Frekuensi berkufi member FOKS Indonesia

Berdasarkan tabel 1, diketahui bahwa $30,77 \%$ rutin berkufi setiap 2-3 hari, sebanyak $23,08 \%$ mendesain khat kufi setiap pekan sekali, sebanyak 19,23\% mendesain khat kufi setiap dua pekan sekali, sebanyak 11,54\% mendesain khat kufi setiap 4-5 hari sekali dan yang gemar mendesain khat kufi sebulan sekali dan setiap hari memiliki prosentase yang sama yaitu 7,69 \%

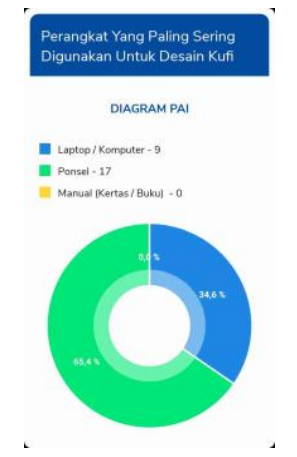

Grafik 3. Perangkat yang digunakan

Berdasarkan grafik 3, diketahui bahwa 65 $\%$ responden menggunakan ponsel dalam mendesain kufi dan $34,6 \%$ sisanya mendesain dengan laptop dan tidak ada yang menggunakan kertas secara manual. Bisa disimpulkan bahwa ponsel adalah perangkat yang paling banyak digunakan untuk mendesain khat kufi murabba'

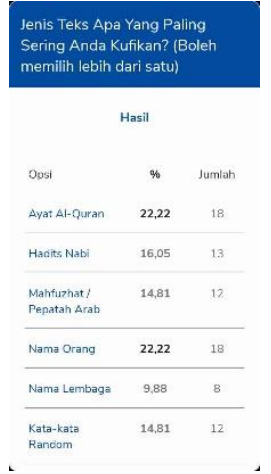

Tabel 2. Jenis Teks yang dikufikan

Berdasarkan tabel 2, diketahui bahwa yang paling sering didesain khat kufinya adalah Ayat Al-Quran dan nama orang dengan prosentase masing-masing $22,22 \%$, sedangkan hadits nabi hanya mencapai prosentase $16,05 \%$. Mahfuzhat dan kata-kata random masingmasing diminati responden sebanyak 14,81\% dan sisanya adalah desain khat kufi untuk nama Lembaga.

Dari statistic tersebut, bisa disimpulkan bahwa teks yang paling disukai untuk didesain khat kufi adalah teks-teks dari ayat Al-Quran dan juga nama orang.

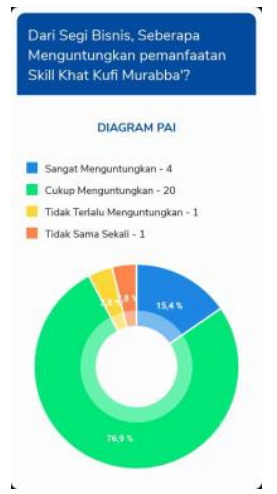

Grafik 4. Prosentase keuntungan skill seni khat kufi murabba' dari segi bisnis

Berdasarkan grafik 4, diketahui bahwa mayoritas responden sebesar $76,9 \%$ menyebut bahwa dari segi bisnis, khat kufi murabba' cukup menguntungkan dan sebanyak 15,4\% menyebut sangat menguntungkan.

Dari statistic tersebut, peneliti mencoba mendapatkan prosentase tingkat keuntungan menekuni seni khat kufi Murabba' dengan rumus skala Likert dengan kriteria berikut : 
Sangat Menguntungkan $=4$

Cukup Menguntungkan = 3

Tidak Terlalu Menguntungkan $=2$

Tidak Menguntungkan Sama sekali $=1$

Berdasarkan kriteria tersebut, berikut intepretasi data dari pertanyaan sebelumnya :

Responden yang menjawab Sangat Menguntungkan $=>4 \times 4=16$

Responden yang menjawab Cukup Menguntungkan $=>20 \times 3=60$

Responden yang menjawab tidak terlalu Menguntungkan $=>1 \times 2=2$

Responden yang menjawab tidak menguntungkan sama sekali $=>1$ X $1=1$

Total Nilai $=79$

Rumus Interval

$\mathrm{I}=100 /$ Jumlah Skor (Likert)

Maka $=100 / 4=25$

Hasil (I) $=25$

(Ini adalah intervalnya jarak dari terendah $0 \%$ hingga tertinggi 100\%)

Berikut kriteria interpretasi skornya berdasarkan interval:

- Angka 0\% - 24,99\% = kurang baik

- Angka 25\% - 49,99\% = cukup

- Angka 50\% - 74,99\% = baik

- Angka 75\% - $100 \%$ = baik sekali

Penyelesaian Akhir

= Total skor / Y x 100

$=79 / 104 \times 100$

$=75,9 \%$, berada dalam kategori "baik sekali"

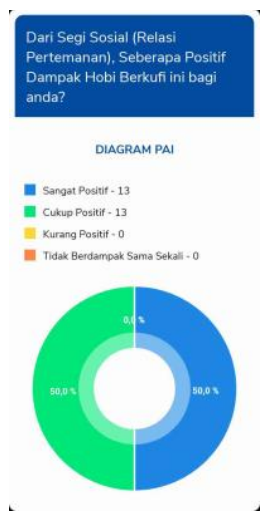

Grafik 6. Dampak positif dari segi sosial

Dari grafik 6, diketahui bahwa setengah dari jumlah responden menyebut bahwa mendesain khat kufi sangat berdampak positif dari segi sosial, dan setengahnya menyebut bahwa itu cukup berdampak positif

Dari statistic tersebut, peneliti mencoba mendapatkan prosentase dampak menekuni seni khat kufi Murabba' dari segi sosial dengan rumus skala Likert dengan kriteria berikut :

Sangat baik $=4$

Cukup baik $=3$

Tidak baik $=2$

Tidak baik $=1$

Berdasarkan kriteria tersebut, berikut intepretasi data dari pertanyaan sebelumnya :

Responden yang menjawab Sangat baik $=>13 \times 4=52$

Responden yang menjawab Cukup baik $=>13 \times 3=39$

Responden yang menjawab tidak terlalu baik $=>0 \times 2=0$

$0 \mathrm{X} 1=0$

Responden yang menjawab tidak baik $=>$

Total Nilai $=91$

Rumus Interval

$\mathrm{I}=100 /$ Jumlah Skor (Likert)

Maka $=100 / 4=25$

Hasil (I) $=25$

(Ini adalah intervalnya jarak dari terendah $0 \%$ hingga tertinggi 100\%)

Berikut kriteria interpretasi skornya berdasarkan interval:

- Angka 0\% - 24,99\% = kurang baik

- Angka 25\% - 49,99\% = cukup

- Angka 50\% - 74,99\% = baik

- Angka 75\% - $100 \%$ = baik sekali

Penyelesaian Akhir

$=$ Total skor $/ \mathrm{Y}$ x 100

$=91 \% / 104 \times 100$

$=87,5 \%$, berada dalam kategori "baik sekali" 
Grafik 7. Prosentase Motivasi Psikologis Kegiatan Desain Khat Kufi

Berdasarkan grafik 7, diketahui bahwa 65 $\%$ responden menjawab Ya, senang sekali, 30, 8 $\%$ menjawab ya, cukup senang, sisanya menjawab "tidak biasa saja"

Dari statistic tersebut, peneliti mencoba mendapatkan prosentase dampak positif menekuni seni khat kufi Murabba' dari segi psikologis dengan rumus skala Likert dengan kriteria berikut :

Sangat Menyenangkan $=4$

Cukup Menyenangkan $=3$

Tidak Terlalu Menyenangkan $=2$

Tidak Menyenangkan $=1$

Berdasarkan kriteria tersebut, berikut intepretasi data dari pertanyaan sebelumnya :

Responden yang menjawab Sangat Menyenangkan $=>17 \times 4=68$

Responden yang menjawab Cukup Menyenangkan $=>8 \times 3=24$

Responden yang menjawab tidak terlalu menyenangkan $=>1 \times 2=2$

Responden yang menjawab tidak menyenangkan sama sekali $=>0 \times 1=0$

Total Nilai $=94$

Rumus Interval

$\mathrm{I}=100 /$ Jumlah Skor (Likert)

Maka $=100 / 4=25$

Hasil (I) $=25$

(Ini adalah intervalnya jarak dari terendah $0 \%$ hingga tertinggi $100 \%$ )

Berikut kriteria interpretasi skornya berdasarkan interval:

Angka 0\% - 24,99\% = kurang baik

Angka 25\% - 49,99\% = cukup

Angka 50\% - 74,99\% = baik

Angka $75 \%-100 \%$ = baik sekali

Penyelesaian Akhir

$=$ Total skor $/ \mathrm{Y}$ x 100

$=94 / 104 \times 100$

$=90,3 \%$, berada dalam kategori "baik sekali"
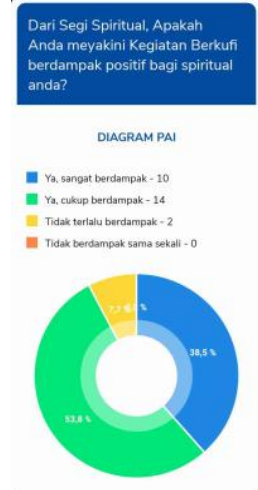

Grafik 8. Prosentase Motivasi Spiritual Aktivitas Berkufi

Berdasarkan Grafik 8, dapat diketahui bahwa $53,8 \%$ responden menyebut bahwa Aktivitas Berkufi cukup berdampak positif, 38,5 $\%$ menjawab sangat berdampak positif dan $7,7 \%$ menjawab tidak terlalu berdampak

Dari statistic tersebut, peneliti mencoba mendapatkan prosentase dampak menekuni seni khat kufi Murabba' dari segi spiritual dengan rumus skala Likert dengan kriteria berikut :

Sangat baik $=4$

Cukup baik $=3$

Tidak baik $=2$

Tidak baik $=1$

Berdasarkan kriteria tersebut, berikut intepretasi data dari pertanyaan sebelumnya :

Responden yang menjawab Sangat baik $=>10 \times 4=40$

Responden yang menjawab Cukup baik $=>14 \times 3=42$

Responden yang menjawab tidak terlalu baik $=>2 \times 2=4$

Responden yang menjawab tidak baik $=>$ $0 \times 1=0$

Total Nilai $=86$

Rumus Interval

$\mathrm{I}=100 /$ Jumlah Skor (Likert)

Maka $=100 / 4=25$

Hasil (I) $=25$

(Ini adalah intervalnya jarak dari terendah $0 \%$ hingga tertinggi 100\%)

Berikut kriteria interpretasi skornya berdasarkan interval:

Angka 0\% - 24,99\% = kurang baik

Angka 25\% - 49,99\% = cukup 
Angka 50\%-74,99\% = baik

Angka $75 \%-100 \%$ = baik sekali

Penyelesaian Akhir

$=$ Total skor $/ \mathrm{Y}$ x 100

$=84 / 104 \times 100$

$=80,7 \%$, berada dalam kategori "baik sekali"

\section{SIMPULAN}

Dari hasil penelitian dapat disimpulkan bahwa dari 26 responden, rata-rata sudah menekuni kufi selama 4 tahun dengan frekuensi mendesain kufi paling banyak adalah 4-5 hari sekali. Perangkat yang paling banyak digunakan adalah ponsel dan teks yang didesain dalam khat kufi murabba' adalah Ayat Al-Quran dan juga nama orang. Motivasi tertinggi yang mendasari kebanyakan dari mereka adalah motivasi psikologis sebesar 90,4\%, diikuti motivasi sosial sebesar $87,5 \%$, motivasi spiritual sebesar $80,7 \%$ dan motivasi bisnis sebesar 75,9\%.

\section{SARAN}

Tingginya motivasi psikologis (untuk menyenangkan hati) dari para penggiat khat kufi murabba' bisa dijadikan acuan untuk mensosialisasikan seni khat Kufi Murabba' dalam rangka meningkatkan tingkat kebahagiaan masyarakat di sekitarnya.

Peneliti juga berharap Para Pemerhati Seni Khat bisa menjadikan penelitian ini sebagai acuan dalam mengembangkan penelitian Khat yang lain

\section{DAFTAR PUSTAKA}

Ba'labka, Zamri. 1981. al-Kitabah al-A'rabiyyah wa al-Samiyyah, Beirut: Dar al-Ilmi Lilmalayyin.

Tabrani Rusyan, dkk 1989 Pendekatan Dalam Proses Belajar Mengajar. CV. Remaja Rosdakarya, Bandung.

Prihartanta, W. (2015). Teori-teori motivasi. Jurnal Adabiya, 1(83), 1-14.

MUSA, N. Y., DAUD, I. C., MUSLIM, N., \& ALIAS, J. (2017). Sejarah Perkembangan Seni Khat dan Pengaruhnya Terhadap Tulisan Jawi di Nusantara (The Developmental History of the Khat and its Influence towards the Jawi Writing System in the Malay Archipelago). MALIM: JURNAL PENGAJIAN UMUM ASIA TENGGARA (SEA Journal of General Studies), 18.

Deskripsi Grup Faceboook FOKS Indonesia (diunduh pada tanggal 30 April 2021 pukul 16:16)

Deskripsi Grup Faceboook FoKS (diunduh pada tanggal 30 April 2021 pukul 16:00) 